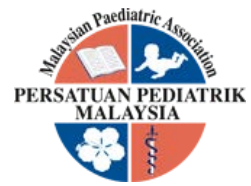

\title{
BILATERAL NEONATAL BREAST ABSCESS IN A WELL-APPEARING NEONATE
}

\author{
Muhammad Yusoff Mohd Ramdzan', Jamil Aiman Mohd Baharuddin', Nordiyana Azmi², \\ Noraida Ramli ${ }^{2}$, Nor Rosidah Ibrahim $^{2}$, Hans Van Rostenberghe ${ }^{2}$
}

\begin{abstract}
Neonatal mastitis and abscess are rare and most often unilateral. Neonatal breast massage for physiological breast hypertrophy is suspected to be a predisposing factor in the case reported here: a 14-day-old neonate with bilateral neonatal breast abscess, treated effectively with intravenous cloxacillin and surgical aspiration.
\end{abstract}

\section{Keywords:}

Breast Abscess, Neonatal Breast Hypertrophy, Mastauxe, Breast Massage, Staph Aureus

\section{Introduction}

Benign proliferation of breast tissue in a neonate is called neonatal mastauxe. It occurs in $70 \%$ of well, term neonates [1] during the first 2 weeks of life and resolves spontaneously by 6 months of life.

Neonatal mastitis is a rare disease. It occurs when the secretory ducts become blocked or when the overlying skin is broken. Neonatal mastitis occurs more in a 2-3:1 male: famale ratio and has a peak incidence in the third week of life [2]. If untreated, it may progress to abscess formation, which may to lead to septicaemia and haematogenous spread to other organs.

Bilateral abscess is rarely reported compared to unilateral cases $[2,4,5]$. It is observed that neonatal breast massage is a potential risk factor for mastitis and abscess formation $[3,4]$

\section{Case Report}

A 14-day-old term, normally delivered, female baby presented with bilateral breast swelling and redness associated with fever for a duration of three days. Since birth, she had mastauxe which was "treated" by a traditional healer with massage of both breasts. Yellowish nipple discharge was seen during massage. Apart from miliaria on day 2
Received: 22 September 2019; Accepted revised manuscript: 31 October 2019

Published online: 05 December 2019

of life, she was well during the first ten days after birth.

During admission, the baby was febrile, but active and not septic-looking. The swellings over both breasts were firm to hard in consistency with erythema of the surrounding skin (Figure 1). There was minimal pus discharge from the nipples. The patient had leucocytosis (22.8 x 109/L, 65\% neutrophils, $20.5 \%$ lymphocytes) and thrombocytosis. C-reactive protein was raised. Blood culture was sterile after 72 hours of incubation. The patient was empirically started on intravenous cloxacillin.

Ultrasound of both breasts revealed partially liquefied abscesses. Needle aspiration was done over the right and left swellings, yielding $3 \mathrm{cc}$ and $1 \mathrm{cc}$ of thick pus respectively. Culture of the

${ }^{1}$ Faculty of Medicine and Health Sciences, Universiti Sains Islam Malaysia, 55100 Ampang, Selangor Malaysia

${ }^{2}$ Department of Paediatrics, School of Medical Sciences, Universiti Sains Malaysia, 16150 Kubang Kerian, Kelantan, Malaysia

Corresponding author: Dr. Muhammad Yusoff Mohd Ramdzan. Faculty of Medicine and Health Sciences, Universiti Sains Islam Malaysia

Tel: 03-42892400; Email: yusofframdzan@gmail.com 
aspirated pus was positive for Staphylococcus aureus - sensitive to cloxacillin, erythromycin and co-trimoxazole, resistant to penicillin $\mathrm{G}$. likely predisposing factor for the development of this child's infection.

Case reports of bilateral neonatal breast abscess are scanty and have almost exclusively originated

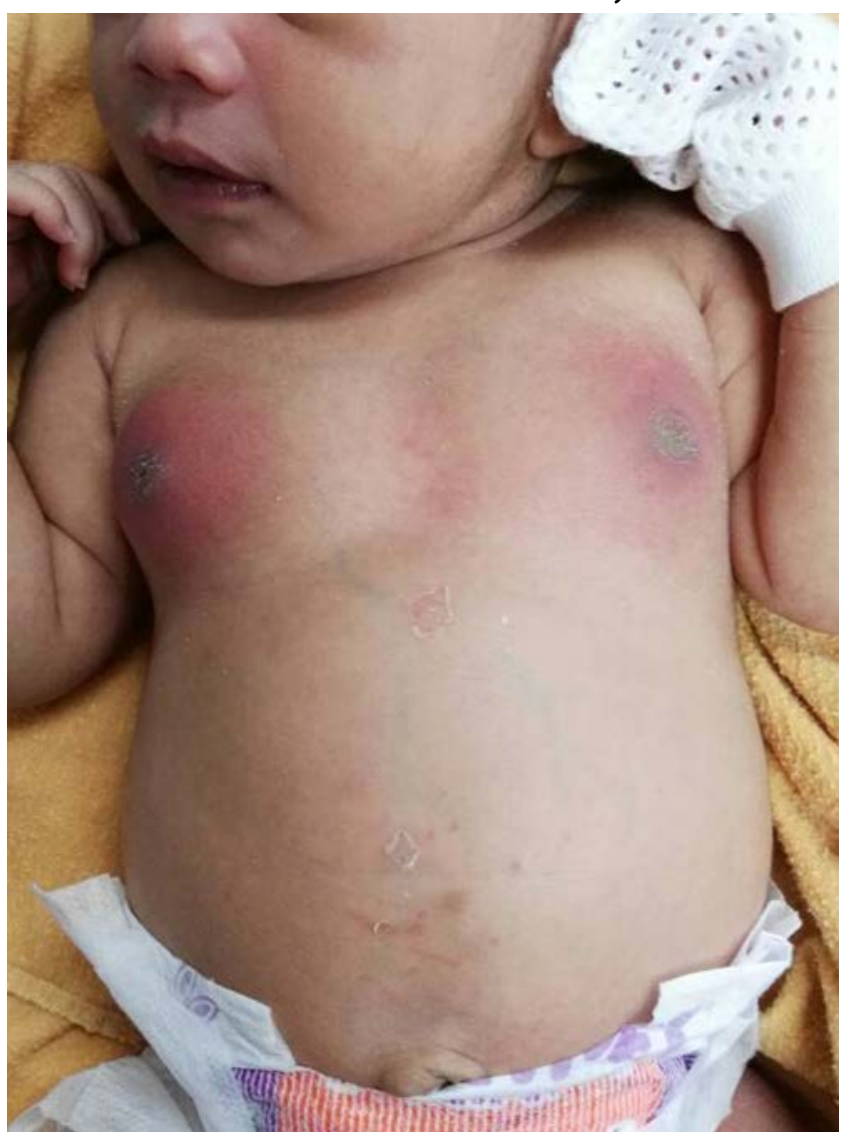

Figure 1: The swellings over both breasts were firm to hard in consistency with erythema of the surrounding skin.

The baby received intravenous cloxacillin for 10 days, during which the pus, breast swelling and erythema gradually improved. At the time of discharge, there was no more pus and the swelling was markedly reduced. She was active, feeding well and afebrile. She was discharged with oral cloxacillin for another 4 days. She was physically back to normal during surgical follow-up clinic review.

\section{Discussion}

Breast abscess is rare among neonates, but bilateral breast abscesses is even much rarer $[4,5]$. This report describes a baby with bilateral breast abscess, without other signs of immunological incompetence. Even though the causal relationship between massage of the breast tissue by a traditional healer cannot be proven, it is a from Asian and African countries where the practice of massage of hypertrophied breast tissue is part of the common culturally accepted practices. One report [4] describes a case series of neonatal mastitis and abscesses in Kashmir. Among the 32 cases in this report, half had undergone massage of the neonatal breast tissue and three cases had presented as bilateral breast abscess. A literature search revealed only three additional case reports of single cases of neonatal bilateral breast abscess in recent history $[2,3,6]$.

There is no evidence that breast massage for neonatal mastauxe carries any benefits, but it may injure the subcutaneous tissue and facilitate the spread of bacteria. In view of the potential longterm sequelae of breast abscess, especially in girls who may experience scarring and problems of dysfunctional and hypoplasia of the affected 
breasts [3,7], the avoidance of potential predisposing factors is important.

Due to the rarity of neonatal mastitis and breast abscess, there is a lack of evidence and a large variation in practice [8]. A 2012 email survey to ED physicians at a children's hospital in Canada showed that management of neonatal mastitis was widely discrepant [7]. Choice and duration of antibiotics varied widely among centres.

The child reported here, had systemic signs of infection (fever) and was admitted to the ward for surgical drainage and IV antibiotics. Severe cases of septicaemia secondary to mastitis/breast abscess have been reported [4] and aggressive treatment may be warranted once abscess formation has taken place.

\section{Conclusion}

Bilateral neonatal breast abscess is an extremely rare condition. This report and other reports from South Asia and Africa support the notion that the traditional practice of massaging the breast tissue in neonatal mastauxe may be an important predisposing factor for this condition. Parental education about the potential harmful effects of massage of neonatal breast tissue is warranted.

\section{References}

[1] Valerio E, Palatron S, Vanzo V, Vendramin S, Cutrone M. Breast disorders of the newborn. Arch Dis Child Educ Pract Ed. 2016 Oct 1;101(5):236-8.

[2] Arunagirinathan A, Duraipandian J, Rangasamy G, Shivekar S, Saban P, Shivekar S. Bilateral breast abscess in a neonate: $A$ case report. IJCRI. 2011 May 1;2(5):26-8.

[3] Erol S, Çınar HG, Zenciroğlu A, Okumuş N. Bilateral breast abscess in a newborn baby. Kafkas J Med Sci 2016; 6(2):142-144.

[4] Masoodi T, Mufti GN, Bhat Jl, Lone R, Arshi S, Ahmad SK. Neonatal mastitis: a clinicomicrobiological study. Journal of neonatal surgery. 2014 Jan;3(1).

[5] Walsh M, Mclntosh K. Neonatal mastitis. Clinical pediatrics. 1986 Aug;25(8):395-9.

[6] Wammanda RD. Bilateral neonatal breast enlargement associated with mastitis. Annals of African Medicine. 2004;3(1):45.

[7] Panteli C, Arvaniti M, Zavitsanakis A. Longterm consequences of neonatal mastitis. Archives of disease in childhood. 2012 Jul 1;97(7):673-4.
[8] Ruwaili NA, Scolnik D. Neonatal mastitis: controversies in management. Journal of clinical neonatology. 2012 Oct;1(4):207. 